\title{
Mitigation of Earthquake Responses Using SMA Supplemented Base-Isolation Devices for Benchmark Building
}

\author{
Ashish R. Akhare \\ Department of Civil Engineering, Indian Institute of Technology (IIT) Bombay, Mumbai, Maharashtra, 400 076, India \\ Department of Civil Engineering, College of Engineering Pune (COEP), Pune, Maharashtra, 411 005, India
}

\section{Keywords}

Shape Memory Alloy (SMA),

Benchmark building,

Base isolation systems,

Structural control,

Near-field earthquake,

Time-history analysis,

SMA supplemented bearings,

Isolation systems.

\begin{abstract}
The efficiency of traditional isolation bearings is doubted for near-field earthquakes because these bearings undergo large displacement. A comparative study of different base isolation systems of base-isolated benchmark building is carried out in the present study. The study is based on assumption that buildings are bi-directionally acted upon by near-field earthquakes for assessing their relative performance in seismic control of the benchmark building. The time history variations of important response parameters and evaluation criteria of the benchmark building has been studied for assessing the effectiveness of the isolation systems. The Shape Memory Alloy (SMA) is utilized with elastomeric bearings and friction bearings to study the effectiveness of SMA wires with different isolators. The benchmark building is modelled as a discrete linear elastic shear structure having three degrees of- freedom at each floor level. Time domain dynamic analysis of this building has been carried out with the help of constant average acceleration Newmark's method and equilibrium of non-linear forces has been taken care by fourth order Runge-Kutta method. The comparative performance of various isolation systems has been studied with uniform and hybrid combinations. The hybrid combination of SMA supplemented bearings works out the better isolation system keeping in view of the percentage reduction in evaluation criteria for smart base-isolated benchmark building. Furthermore, it is shown that, the functionality of SMA wire is not efficient with Lead Rubber Bearing system, as it is able to control displacement but increases the acceleration, base shear, story drift and isolation forces.
\end{abstract}

\section{Introduction}

It is established that, in the catastrophic event such as an earthquake, the use of isolators at the base of a building significantly changes transfer of frequency content of ground to the superstructure and mitigates devastating effects of earthquakes. This however, highly depends on which isolation system is adopted for a particular building. The isolation systems designed for the building are broadly classified into elastomeric type and friction type. The elastomeric bearing consists of rubber like material which makes them flexible enough (and hence less stiff) for horizontal excitations. With the provision of steel shims in alternate layers, the vertical stiffness increases for elastomeric bearing for carrying vertical weight of the superstructure. are widely under stress.

The lead core is sometimes introduced at the centre of elastomeric bearing, which is then called as Lead Rubber Bearing (LRB) or New Zealand (NZ) bearing. The purpose of lead core is twofold. First is to give enough strength in horizontal direction in the event of minor ground tremors or wind like vibrations, and the second is to help in increasing hysteretic damping, thereby increasing energy dissipation. Jangid (2003) [1].

Literature review indicates past studies done about various isolation systems used for buildings and demonstrated in Park et.al. (2002) [2] Su et.al. (1989a) [3], (1989b) [4], Filiatrault and Cherry (1988) [5]. It shows use of traditional isolator bearings and combinations thereof However, use of SMA with traditional bearings such as elastomeric bearings, friction bearing etc. are still in nascent stage which need more investigation. In this study, the use of SMA with elastomeric bearing, lead rubber bearing, friction pendulum bearing, R-FBI bearing and their hybrid combinations thereof are investigated. The benchmark building as adopted by Narsimhan et. al. (2006)[6] is used and modelled as lumped mass building having three degrees of freedom at each floor level. Time domain dynamic analysis of this building is carried out with constant average acceleration Newmark's method. The nonlinear SMA forces are modelled using GraesserCozzarelli (1991) [7] model with the help of fourth order Runge-Kutta method. So, various isolation systems have been proposed to obtain effective control over the structural response and the isolator displacement of a base-isolated benchmark building. By comparing them, conclusions about the merits and demerits of various proposed systems can be done. Therefore, the aim of the present study is (i) to compare and find the effects of different proposed SMA supplemented isolation devices with elastomeric and friction bearings for base isolated structure. (ii) to know the behaviour of SMA with ERB, LRB, FPS, RFBI bearings on the seismic performance of base-isolated benchmark building. (iii) to find effective and better isolation system for benchmark building. (iv) To know functionality of SMA with traditional bearing systems.

\section{Modelling of Base Isolated Benchmark Building}

The orientation and placement of isolation devices in a building decides the seismic resistance of the building and governing of its structural response. To investigate the effectiveness of an isolation system, a base-isolated benchmark building has been selected for analysis. Four different types of traditional bearings such as ERB, LRB, FPS and RFBI have been chosen for the present study. Well-defined analytical benchmark problems have been developed for studying response control strategies for building and bridge structures subjected to seismic excitation, by broad consensus effort of the American Society of Civil Engineers (ASCE) structural control committee. Narasimhan et al. (2006) [6] have developed the smart base-isolated benchmark problem, based on input from the ASCE structural control committee, with the capability to model three different kinds of base isolation systems: linear elastomeric systems with low damping or supplemental high damping, frictional systems,
Anding Author: ashishakhare@gmail.com

(A.R.Akhare Orcid: 0000-0001-8564-2886)
Received 24 July 2021 Revised 12 Aug 2021 Accepted 18 Aug 2021

Civil Engineering Beyond Limits 4 (2021) 22-30 2687-5756 (C) 2019 ACA Publishing. All rights reserved https://doi.org/10.36937/cebel.2021.004.005 
bilinear or nonlinear elastomeric systems, or any combination thereof. Fig. 1 (a) and (b) shows the plan and elevation of an eightstoried steel-braced frame of the base-isolated benchmark building.

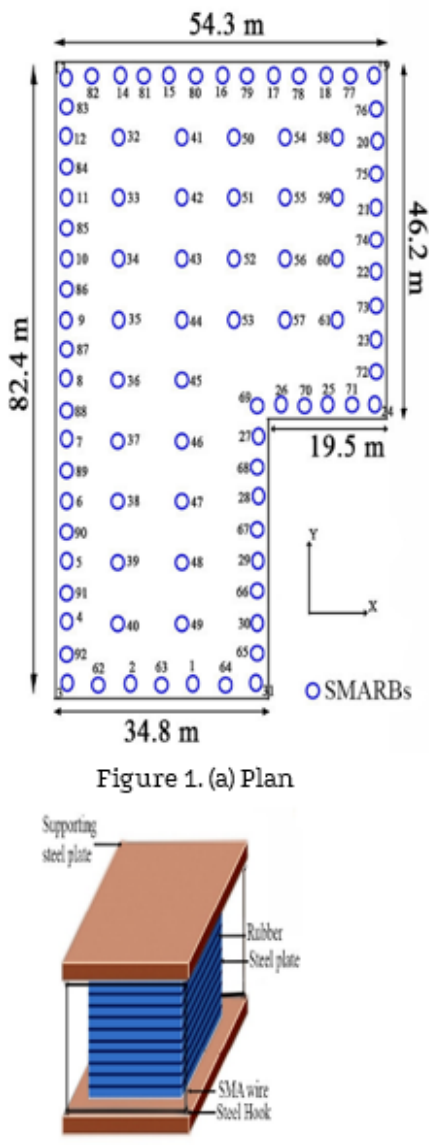

Figure 1. (c) Isolator with SMA

$7|7| 7|7| 7|1 / 7| 7|7| 7 \mid 7$ Figure 1. (b) Elevation

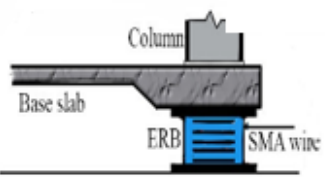

Figure 1. (d) Sectional view of the Isolator with SMA

Figure 1. Benchmark Base - Isolated Building with SMA supplemented Isolation Bearings

The floor plan of the building is L-shape up to the sixth floor and rectangular shape for remaining floors. The overall plan of the building is $82.4 \mathrm{~m}$ long and $54.3 \mathrm{~m}$ wide. The superstructure steel frame is mounted on a concrete base slab. The concrete base slab is monolithic with concrete beams. Drop panels are provided below each column. The SMA supplemented bearings are installed in between each drop panel and the sub-structure. The building is idealized as a three-dimensional linear elastic structure. The total weight of the structure is $203113.4013 \mathrm{kN}$. In this study, the isolation system consists of 92 isolation devices as shown in Fig. 1 (a). In the benchmark problem, these bearing locations are adopted to get equal contribution of all the isolation bearings in the response of the base-isolated building. Therefore, it is considered that the SMA does not deform beyond its maximum strain limit due to the adopted distribution. The superstructure is modelled as a discrete linear elastic shear structure. Floor slabs and the base mat are assumed to be rigid in plane. The superstructure and the base are modelled using three master degrees of freedom (DOF) per floor at the centre of mass. The combined model of the superstructure (24 DOF) and isolation system (3 DOF) consists of total 27 DOF. All twenty-four modes in the fixed-base case are used in modelling the superstructure.

The superstructure damping ratio is assumed to be $5 \%$ in all fixedbase modes. The assumptions made for the structural system under consideration are (i) the superstructure remains linear during seismic loading, (ii) the floors are assumed to be rigid and the masses are lumped at the centre of mass of floors, (iii) three degrees of freedom (DOF) are assumed at each floor at lumped mass location, and (iv) fixed base structure consists of $24 \mathrm{DOF}$, and all modes are considered in the analysis. Equations of motion are developed with the fixed-base properties used for the linear superstructure. With linear behaviour of the superstructure, the equations of motion can be written as

$\left[M_{s}\right]\left\{\ddot{x}_{s}\right\}+\left[C_{s}\right]\left\{\dot{x}_{s}\right\}+\left[K_{s}\right]\left\{x_{s}\right\}=-\left[M_{s}\right]\{r\}\left(\ddot{x}_{g}+\ddot{x}_{b}\right)$

where $\left[M_{s}\right],\left[C_{s}\right]$ and $\left[K_{s}\right]$ are the lumped mass, damping, and stiffness matrices of size $24 \times 24$ for the fixed base structure, respectively; $\left\{x_{s}\right\}$ $=\left\{x_{1}, x_{2}, \ldots . x_{8}\right\}^{T},\left\{\dot{x}_{s}\right\}$ and $\left\{\ddot{x}_{s}\right\}$ are the unknown relative floor displacement, velocity, and acceleration vectors, respectively of size $24 \mathrm{x} \mathrm{1}$; the subscript numbers 1 to 8 represents the floor numbers; $x_{1}$ represent the vector of size $3 \times 1$ for considered three DOF at first floor level; $\left\{\ddot{x}_{g}\right\}$ and $\left\{\ddot{x_{b}}\right\}$ are the acceleration vectors of ground and base mass, respectively of size $3 \times 1$; and [r] is the influence coefficient matrix of size $24 \times 3$.

The non-linear behavior of SMA is modelled using the GraesserCozzarelli model, and the forces in the bearings are transformed to the centre of mass of the base using a rigid base-slab assumption. All the SMA supplemented isolation bearings can be modelled individually or globally by equivalent lumped elements at the centre of mass of the base. The governing equation of motion for the base mass is written as

$$
\begin{gathered}
{[r]^{T}\left[M_{s}\right]\left[\left\{\ddot{x}_{s}\right\}+[r]\left(\left\{\ddot{x}_{g}\right\}+\left\{\ddot{x}_{b}\right\}\right)\right]+\left[m_{b}\right]\left(\left\{\ddot{x}_{g}\right\}+\left\{\ddot{x}_{b}\right\}\right)+\left\{F_{b}\right\}} \\
=0
\end{gathered}
$$

where $\left[m_{b}\right]$ is the diagonal mass matrix of the base mass of size $3 \times 3$; $\left\{F_{b}\right\}$ is the vector containing forces of isolation device (SMA + ERB) of size $3 \times 1$; and $[r]^{T}$ represents the transpose of the influence coefficient matrix $[r]$.

The equations of motion of base isolated structure are solved numerically using Newmark's method of step-by-step integration. The linear variation of acceleration over a small time interval, $\delta_{\mathrm{t}}=$ $0.001 \mathrm{~s}$ is considered.

\section{SMA Supplemented ERB (SMARB) Isolation System}

SMA is used along with ERB isolation device for the need of zero residual deformation. The primary work of horizontal flexibility and vertical stiffness is provided by ERB. ERB consists of steel and rubber material in alternate layers. The steel shims provide high vertical stiffness which helps to control the

rocking effects of the structure due to vertical vibrations caused by the earthquake. SMA is used along with the ERB due to its superelasticity and damping capabilities which minimize the peak and residual isolator deformation. The SMA is wound along the corners of the ERB to provide hysteretic damping and also to add lateral stiffness along the direction of the seismic force, as shown in Fig. 1 (c). The restoring forces generated by the $i^{\text {th }}$ isolation and SMA device in the $x$ and $y$ directions can be mathematically modelled as

$$
\begin{aligned}
& f_{x i}=k_{b i} u_{x i}+c_{b i} \dot{u}_{x i}+f_{s x i} \\
& f_{y i}=k_{b i} u_{y i}+c_{b i} \dot{u}_{y i}+f_{s y i}
\end{aligned}
$$

where $f_{x i}$ and $f_{y i}$ are the bearing forces in the $\mathrm{x}$ and $\mathrm{y}$ directions, respectively; $k_{b i}$ is the stiffness of the ERB; $c_{b i}$ is the damping of viscous ERB; $\dot{u}_{x i}, \dot{u}_{y i}$ and $u_{x i}, u_{y i}$ represent the relative velocities and displacements of the $i^{\text {th }}$ isolation device in the $\mathrm{x}$ and $\mathrm{y}$ directions, respectively, and $f_{s x i}, f_{s y i}$ are the hysteretic forces produced by the SMA in the $\mathrm{x}$ and $\mathrm{y}$ directions, respectively.

If $k_{b i}$ and $k_{t i}$ represent the lateral stiffness of the ERB and SMA, respectively, then 


$$
\begin{aligned}
& K_{b}=\sum_{i=1}^{92} k_{b i} \\
& K_{t}=\sum_{i=1}^{92} k_{t i}
\end{aligned}
$$

are the resultant stiffness of the ERB and SMA devices, respectively. The isolation period, $\mathrm{T}$ is defined follows

$T_{b}=2 \pi \sqrt{\frac{M}{K_{b}+K_{t}}}$

where $\mathrm{M}$ is the total lumped mass of superstructure and base mass. The damping coefficient of the $i^{\text {th }}$ bearing is expressed as

$$
C_{b i}=2 m_{i} \omega_{b} \xi_{b}
$$

in which, $m_{i}$ is the mass of superstructure and base mass on the $i^{\text {th }}$ isolation device; $\xi_{b}$ is damping ratio of the ERB; and $\omega_{b}$ is the isolation frequency defined as

$$
\omega_{b}=\frac{2 \pi}{T_{b}}
$$

It is to be noted that the $\omega_{b}$ and $T_{b}$ represents the fundamental frequency and time period of base-isolated structure if superstructure behaves rigidly. However, due to flexibility of superstructure the actual fundamental frequency and time period may slightly deviate from the above values.

\section{Nonlinear Force - Deformation Modelling of SMA}

SMA can be used for seismic resistant applications but very limited attempts are made in this regard as suggested by wilson and Wesolowsky (2005) [8]. The two main properties of SMA are shape memory effect and superelasticity. While shape memory effect is achieved through thermal gradient induced transformation, the superelasticity is achieved through stress induced transformation. The phase transformation of SMA is achieved by applying load on it. This is achieved only at temperature greater than $A_{f}$. The shape memory effect is not useful in base isolation. SMA manufacturers provide required materials which are used in available temperature ranges as given by Ozbulut and Harlebaus (2010) [9], Ozbulut et.al. (2011) [10]. In this study, it is assumed that temperature to cause superelasticity effect is available at ambient temperature. There are many models developed by the researchers such as Graesser Cozzarelli (1991, 1994) [7, 11], Wilde et.al. (2000) [12], Ren (2007) [13].

In this work, Graesser - Cozzarelli (G - C) model is used. This model can implement both superelasticity and shape memory effect, Ghodke and Jangid (2016) [14]. Equations of force-deformation relationship which represents the super-elasticity of SMA to obtain a nonlinear force for the $i^{\text {th }}$ SMA device are given as

$\dot{f}_{s x i}=k_{a i}\left[\dot{u}_{x i}-\left|\dot{u}_{x i}\right|\left|\frac{f_{s x i}-\beta_{x i}}{F_{y s i}}\right|^{n-1}\left(\frac{f_{s x i}-\beta_{x i}}{F_{y s i}}\right)\right]$

$\dot{f}_{s y i}=k_{a i}\left[\dot{u}_{y i}-\left|u_{y l}\right|\left|\frac{f_{s y i}-\beta_{y i}}{F_{y s i}}\right|^{n-1}\left(\frac{f_{s y i}-\beta_{y i}}{F_{y s i}}\right)\right]$

$\beta_{x i}=\alpha_{s} k_{a i}\left[u_{x i}-\frac{f_{s x i}}{k_{a i}}+f_{t}\left|u_{x i}\right|^{c^{\prime}} \operatorname{erf}\left(a^{\prime} u_{x i}\right)\right]$

$\beta_{y i}=\alpha_{s} k_{a i}\left[u_{y i}-\frac{f_{s y i}}{k_{a i}}+f_{t}\left|u_{y i}\right|^{c^{\prime}} \operatorname{erf}\left(a^{\prime} u_{y i}\right)\right]$

where $n$ is a constant controlling the sharpness of transition of hysteresis while loading changes its nature; $\beta_{x i}$ and $\beta_{y i}$ are the back stress in $x$ and $y$ directions, respectively;

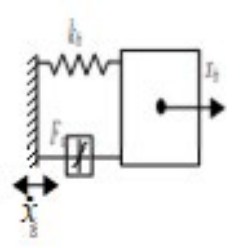

(a)
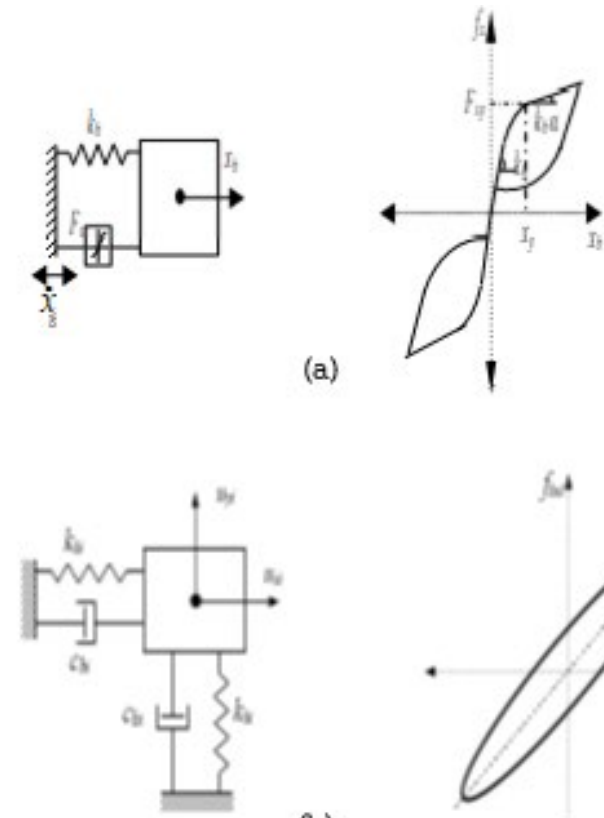

(b)
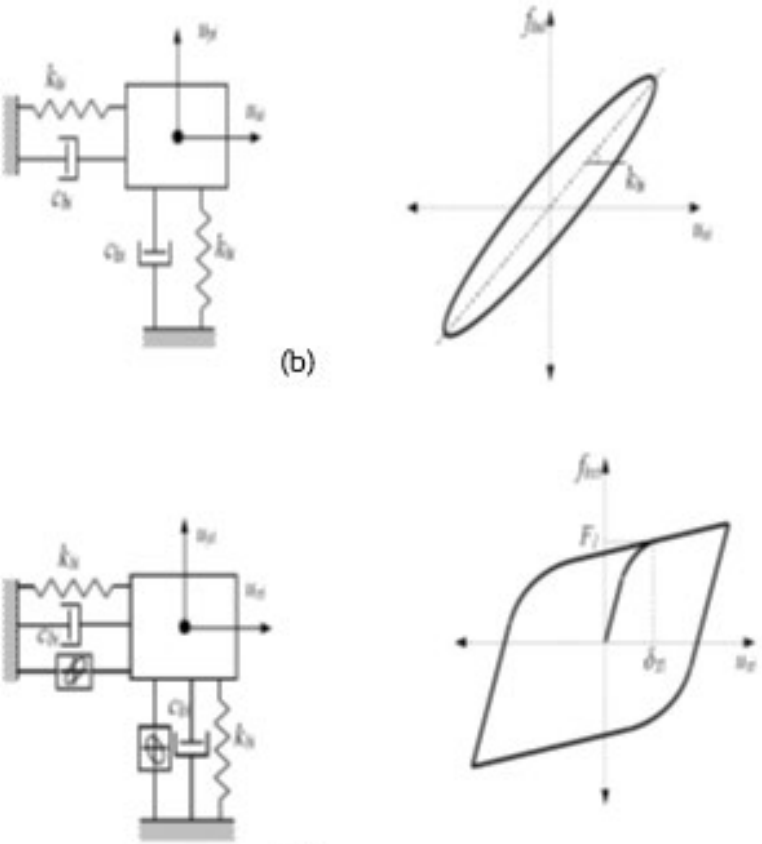

(c)
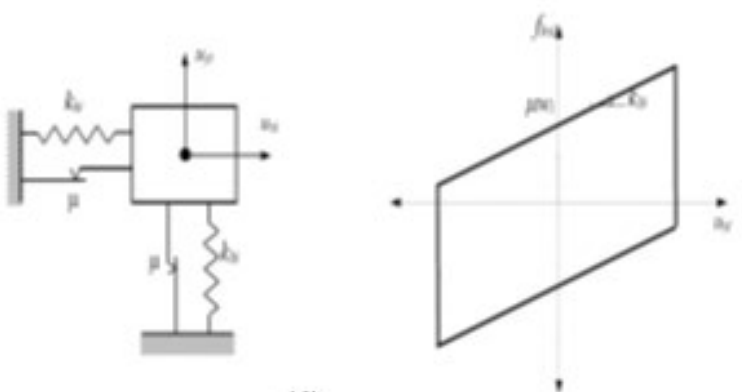

(d)

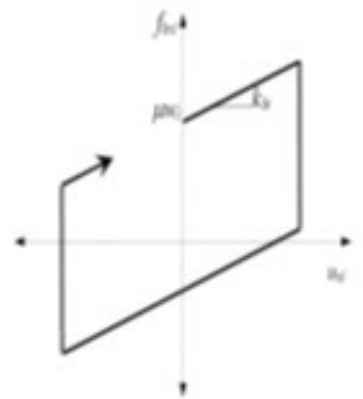

(e)

Figure 2. Mathematical models and force-displacement diagrams of a) SMA, b) ERB, c) N-Z d) FPS, and e) R-FBI isolators 
$\alpha_{s}$ is the ratio of transformation to austenite stiffness of SMA; $c^{\prime}$ is a constant controlling the slope of the unloading path; $f_{t}$ is a constant controlling the type and size of hysteresis; $a^{\prime}$ is a constant controlling the amount of elastic recovery during unloading; (') is the ordinary time derivative; $\operatorname{erf}\left(f_{x}\right)$ is the error function of the argument $f_{x}$,

$\operatorname{erf}\left(f_{x}\right)=\frac{2}{\pi} \int_{0}^{f_{x}} e^{-t^{2}} d t$

The initial austenite stiffness of the $i^{\text {th }}$ isolator, $k_{a i}$ expressed as

$k_{a i}=\frac{F_{y s i}}{\delta_{s}}$

where $\delta_{s}$ is a yield displacement of SMA; and $F_{y s i}$ is the transformation force of the $i^{\text {th }}$ isolator and can be obtained as

$F_{y s i}=F_{s o} m_{i} g$

Where $F_{\text {so }}$ and $g$ are the normalized transformation strength of SMA and a gravitational acceleration, respectively. The mathematical model of Non-linear force deformation model of SMA is shown in Fig. 2 (a) and of ERB is represented in Fig. 2 (b)

Based on the above considered model, a MATLAB program has been coded using higher order Runge-Kutta method to simulate the hysteretic behavior of SMA under external loading. Numerical values used for the parameters characterizing the hysteresis behaviour of the SMA are provided in Table 1.

Table 1. Constants for traditional bearing and SMA

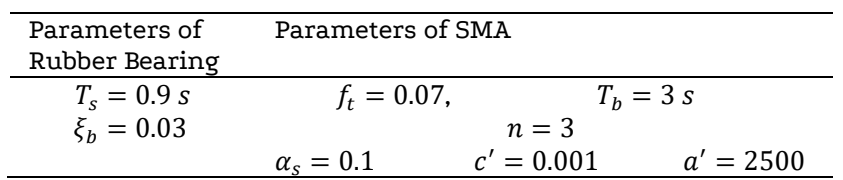

\section{SMA Supplemented New Zealand Bearing (SMANZ) Isolation System}

In Lead Rubber Bearing (LRB) a central lead core is inserted to provide additional means of energy dissipation, and initial rigidity against minor earthquakes and winds as proved by Skinner et al., (1975) [15] Robinson, (2000) [16], Matsagar and Jangid, (2004) [17], Jangid, (2007) [18]. The lead core reduces the isolation displacement by virtue of its energy absorbing capacity. The mathematical modelling is done with the help of non-linear model based on Bouc-Wen theory hence called as Wen's model as shown in Fig. 2 (c). In this study, the SMA is used in combination with $\mathrm{N}-\mathrm{Z}$ bearing to call it as SMANZ isolation system. Therefore, Graezzer - Cozzarelli model and Bouc-Wen model is used in combination. The restoring force developed in SMANZ isolation system is therefore given by,

$f_{x i}=k_{b i} u_{x i}+c_{b i} \dot{u}_{x i}+\left(1-\alpha_{l}\right) F_{1} Z_{x i}+f_{s x i}$

$f_{y i}=k_{b i} u_{y i}+c_{b i} \dot{u}_{y i}+\left(1-\alpha_{l}\right) F_{1} Z_{y i}+f_{s y i}$

where $f_{s x i}$ and $f_{s y i}$ are having same meaning as explained before, $F_{1}$ is the yield force of the bearing; $\alpha_{l}$ is an index which represent the ratio of post to pre-yielding stiffness; $k_{b i}$ is the initial stiffness of the bearing; $c_{b i}$ is the viscous damping of the bearing; $Z_{x i}$ and $Z_{y i}$ are the unitless components in $x$ and $y$-directions, respectively for the $i^{\text {th }}$ isolator governed by Bouc-Wen model which is expressed as (Casciati 1989)

$$
\begin{aligned}
& \delta_{y l}\left\{\begin{array}{l}
\dot{Z}_{x i} \\
\dot{Z}_{y i}
\end{array}\right\} \\
& =\alpha\left\{\begin{array}{l}
\dot{u}_{x i} \\
\dot{u}_{y i}
\end{array}\right\} \\
& -\beta\left[\begin{array}{cc}
Z_{x i}{ }^{2}\left(\lambda \operatorname{sign}\left(\dot{u}_{x i} Z_{x i}\right)+\beta\right) & Z_{x i} Z_{y i}\left(\lambda \operatorname{sign}\left(\dot{u}_{y i} Z_{y i}\right)+\beta\right) \\
Z_{x i} Z_{y i}\left(\lambda \operatorname{sign}\left(\dot{u}_{x i} Z_{x i}\right)+\beta\right) & Z_{y i}{ }^{2}\left(\lambda \operatorname{sign}\left(\dot{u}_{y i} Z_{y i}\right)+\beta\right)
\end{array}\right]\left\{\begin{array}{l}
\dot{u}_{x i} \\
\dot{u}_{y i}
\end{array}\right\}
\end{aligned}
$$

where $\delta_{y l}$ is the yield displacement; $\alpha, \beta$ and $\lambda$ are the constants which controls the shape of hysteretic loop.

\section{SMA Supplemented Friction Pendulum System (SMAFPS) Isolation System}

In FPS system, frictional force is proportional to the mass of the structure, and the centre of mass and centre of resistance of the sliding support coincides. Consequently, the torsional effects produced by the asymmetric building are diminished. The mathematical model and ideal force-deformation behaviour of the isolator is shown in Fig. 2 (d). In this study, the SMA wires are used along with FPS bearing system. Hence contribution by SMA is added in order to get total frictional force in SMAFPS in $x$ and $y$ directions as

$f_{x i}=k_{b i} u_{x i}+\mu \omega_{i} Z_{x i}+f_{s x i}$

$f_{y i}=k_{b i} u_{y i}+\mu \omega_{i} Z_{y i}+f_{s y i}$

where $\mu$ is the friction coefficient; $\omega_{i}=m_{i} g$ is the weight of the structure and base on the $i^{\text {th }}$ isolator; $Z_{x i}$ and $Z_{y i}$ are hysteretic dimensionless parameters governed by Equation $19 ; k_{b i}$ is the bearing stiffness provided by virtue of inward gravity action at the concave surface. The system is characterized by the isolation time period $\left(T_{b}\right)$ that depends upon the radius of curvature of the concave surface and the friction coefficient $(\mu)$. The isolation stiffness, $k_{b i}$ is adjusted such that the specified value of the isolation period is achieved.

\section{SMA Supplemented Resilient Bearing (R-FBI) Isolation System}

Resilient friction base isolator (R-FBI) system is characterized by concentric layers of Teflon-coated plates in friction contact with each other, and a central rubber core, Mostaghel and Khodaverdian, (1987) [19]; Mostaghel and Mortazavi, (1991) [20]. The mathematical model and ideal force-deformation behavior of the bearing is shown in Fig. 2 (e). The SMA are used in combination with R-FBI and therefore the resisting forces in the SMARF isolation system in $\mathrm{x}$ and $\mathrm{y}$ direction are given as

$f_{x i}=k_{b i} u_{x i}+c_{b i} \dot{u}_{x i}+\mu \omega_{i} Z_{x i}+f_{s x i}$

$f_{y i}=k_{b i} u_{y i}+c_{b i} \dot{u}_{y i}+\mu \omega_{i} Z_{y i}+f_{s y i}$

where $Z_{x i}$ and $Z_{y i}$ are hysteretic dimensionless parameters governed by equation 19 as given in Lead Rubber (N-Z) Bearing. $f_{s x i}$ and $f_{s y i}$ are as calculated in equation 10 and 11, respectively.

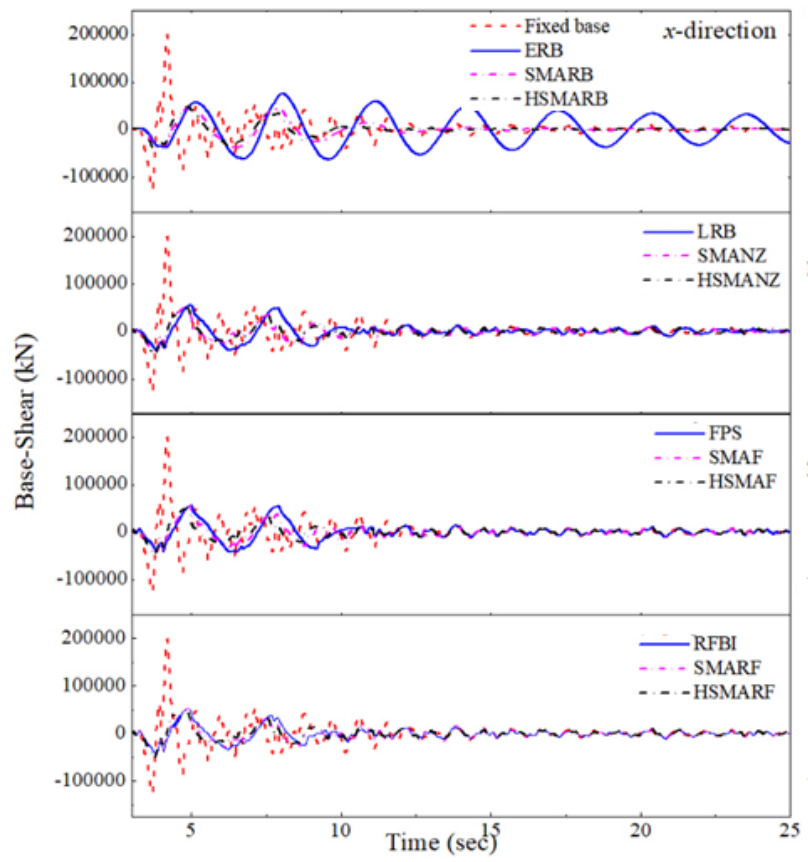

Figure 3. Time variation of base-shear for base-isolated building under Sylmar, 1994 earthquake 


\section{Earthquake Ground Motions}

The earthquake ground motion has peaks of acceleration in positive as well as negative values and also has various amplitudes and occur at various time intervals without any regular pattern. In this study, only horizontal motions have been considered in the benchmark problem. The historical ground motions given in benchmark problem have been considered in this study. Out of these, most of the earthquakes are near-fault. Jangid and Kelly (2001) [21] investigated that near-fault earthquakes have a significant impact on baseisolated buildings. It is established that base-isolated buildings have large residual deformations when it is subjected to near-fault earthquake. Near-fault earthquakes have long period pulses, large ground displacement, and permanent ground displacement. These earthquakes are applied bi-directionally in such a way that the fault normal (FN) and fault parallel (FP) directions of the earthquake are along the $x$ and $y$ directions of the benchmark building, respectively. Details of these ground motions are given in Table 2.

Table 2. Details of Earthquake Ground Acceleration Records

\begin{tabular}{llll}
\hline Serials & Earthquake & Year & Station \\
\hline EQTH1 & Imperial Valley & 19.05 .1940 & El Centro \\
EQTH2 & Kobe & 16.01 .1995 & JMA \\
EQTH3 & Northridge & 17.01 .1994 & Sylmar \\
EQTH4 & Northridge & 17.01 .1994 & Newhall \\
\hline
\end{tabular}

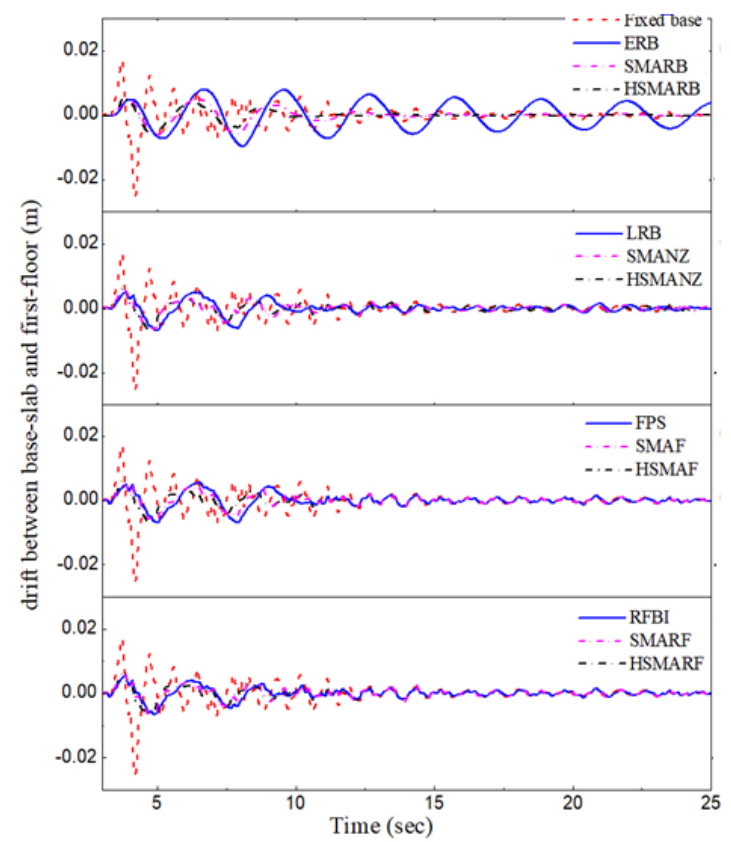

Figure 4. Time variation of base-shear for base-isolated building under Sylmar, 1994 earthquake

\section{Evaluation Criteria}

The Table 3 shows performance evaluation criteria. The response quantities are normalized by corresponding uncontrolled response values as given in Table 4. Table 5 shows comparison between various isolation systems. The first eight cases in Table 5 are for uniform isolation types and last four are for hybrid combination of isolation type. The evaluation criteria as given in benchmark problem, is adopted in this study which is based on both peak and RMS responses of the building as tabulated in Table 3. In this Table 3, $V_{b}$ and $V_{s}=$ Base and Structural shear, $F_{b}=$ Isolation force; RMS = Root mean square, Corresponding uncontrolled response quantity $a_{f}=$ top floor acceleration; $d_{f}=$ Inter story drift, $\mathrm{t}=$ Time; $\|$. $\|=$ Modulus of Vector magnitude; The relative performance of different isolation systems is evaluated based on the response values of corresponding uncontrolled fixed based structure. Hereinafter, these response values of Table 4 are called as uncontrolled response values. The selected seven earthquake time histories (EQTH) as applied to fixed based structure, gives large difference in peak acceleration values. This indicate that selected seven EQTH are having different characteristics.

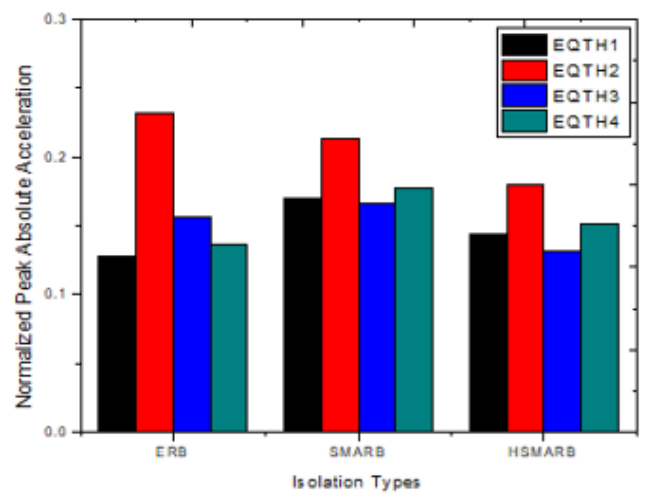

Figure 5. Variation of Normalized Peak Absolute Acceleration for different Earthquakes and Isolation Types

Table 3. Evaluation Criteria

\begin{tabular}{|c|c|c|}
\hline Symbol & Observation & Equation \\
\hline \multirow[t]{2}{*}{$J_{1}$} & \multirow[t]{2}{*}{ Peak base shear } & $\max \left\|\left(V_{b}(t)\right)\right\|$ \\
\hline & & $J_{1}-\overline{\max \left\|\left(\hat{V}_{b}(t)\right)\right\|}$ \\
\hline \multirow[t]{2}{*}{$J_{2}$} & \multirow[t]{2}{*}{ Peak story shear } & $\max \left\|\left(V_{s}(t)\right)\right\|$ \\
\hline & & $\overline{\max \|\left(\hat{V}_{s}(t)\right)}$ \\
\hline \multirow[t]{2}{*}{$J_{3}$} & \multirow[t]{2}{*}{ Peak base displacement } & $\max \left\|\left(D_{b}(t)\right)\right\|$ \\
\hline & & $\max \|\left(\widehat{D}_{b}(t)\right)$ \\
\hline \multirow[t]{2}{*}{$J_{4}$} & \multirow[t]{2}{*}{ Peak story drift } & $\max \left\|\left(d_{f}(t)\right)\right\|$ \\
\hline & & $\overline{\max } \|\left(\hat{d}_{f}(t)\right)$ \\
\hline \multirow[t]{2}{*}{$J_{5}$} & \multirow{2}{*}{$\begin{array}{ll}\text { Peak } & \text { absolute } \\
\text { acceleration } & \end{array}$} & $\max \left\|\left(a_{f}(t)\right)\right\|$ \\
\hline & & $\max \left\|\left(\hat{a}_{f}(t)\right)\right\|$ \\
\hline \multirow[t]{2}{*}{$J_{6}$} & \multirow{2}{*}{$\begin{array}{l}\text { Peak cumulative } \\
\text { isolation force }\end{array}$} & $\max \left\|\left(F_{b}(t)\right)\right\|$ \\
\hline & & ${ }_{6}-\overline{\max \left\|\left(\hat{F}_{b}(t)\right)\right\|}$ \\
\hline \multirow[t]{2}{*}{$J_{7}$} & \multirow[t]{2}{*}{ RMS base displacement } & $=\frac{\max \|\left(R M S D_{b}(t)\right) \mid}{}$ \\
\hline & & $\overline{\max \|(\widehat{R M S D}}(t))$ \\
\hline \multirow[t]{2}{*}{$J_{8}$} & \multirow[t]{2}{*}{$\begin{array}{l}\text { RMS } \\
\text { acceleration }\end{array}$} & $\max \|\left(R M S a_{f}(t)\right)$ \\
\hline & & $\max \|\left(R \widehat{M S a}_{f}(t)\right)$ \\
\hline
\end{tabular}

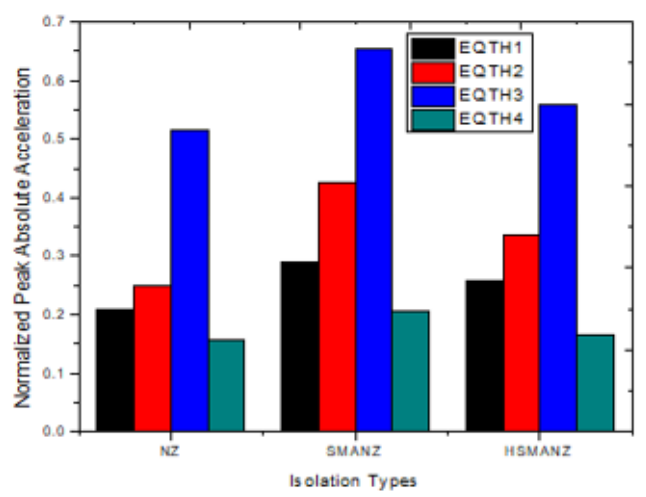

Figure 6. Variation of Normalized Peak Absolute Acceleration for different Earthquakes and Isolation Types 


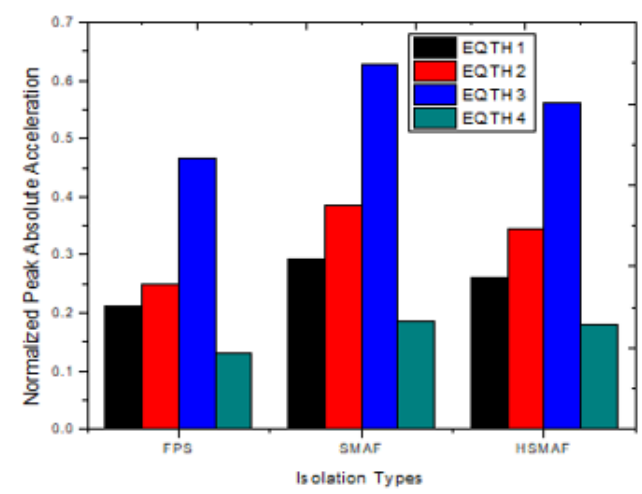

Figure 7. Variation of Normalized Peak Absolute Acceleration for different Earthquakes and Isolation Types

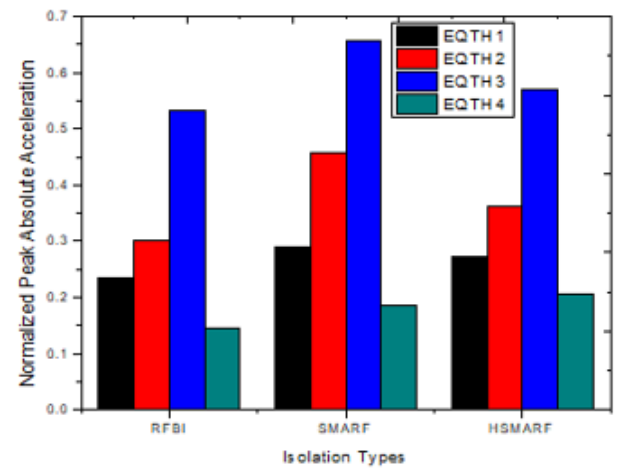

Figure 8. Variation of Normalized Peak Absolute Acceleration for different Earthquakes and Isolation Types

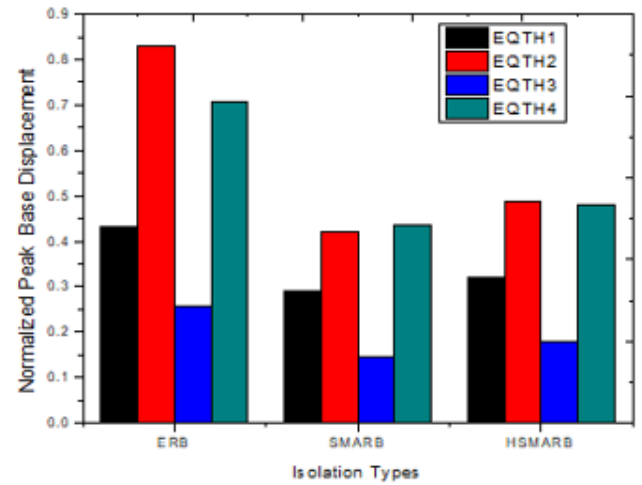

Figure 9. Variation of Normalized Peak Base Displacement for different Earthquakes and Isolation Types

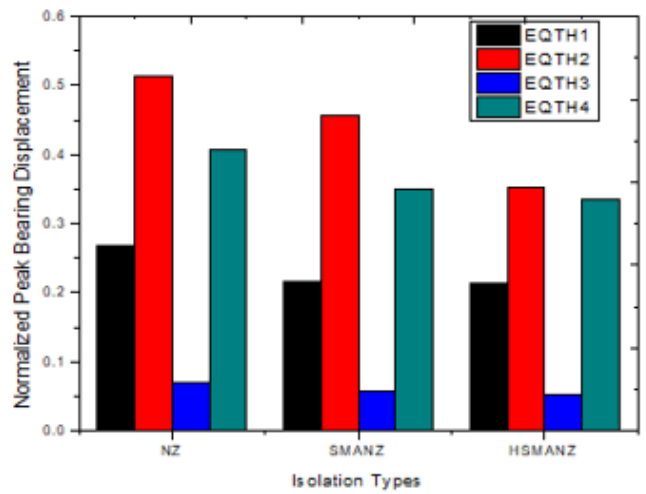

Figure 10. Variation of Normalized Peak Base Displacement for different Earthquakes and Isolation Types
Table 4. Uncontrolled response values

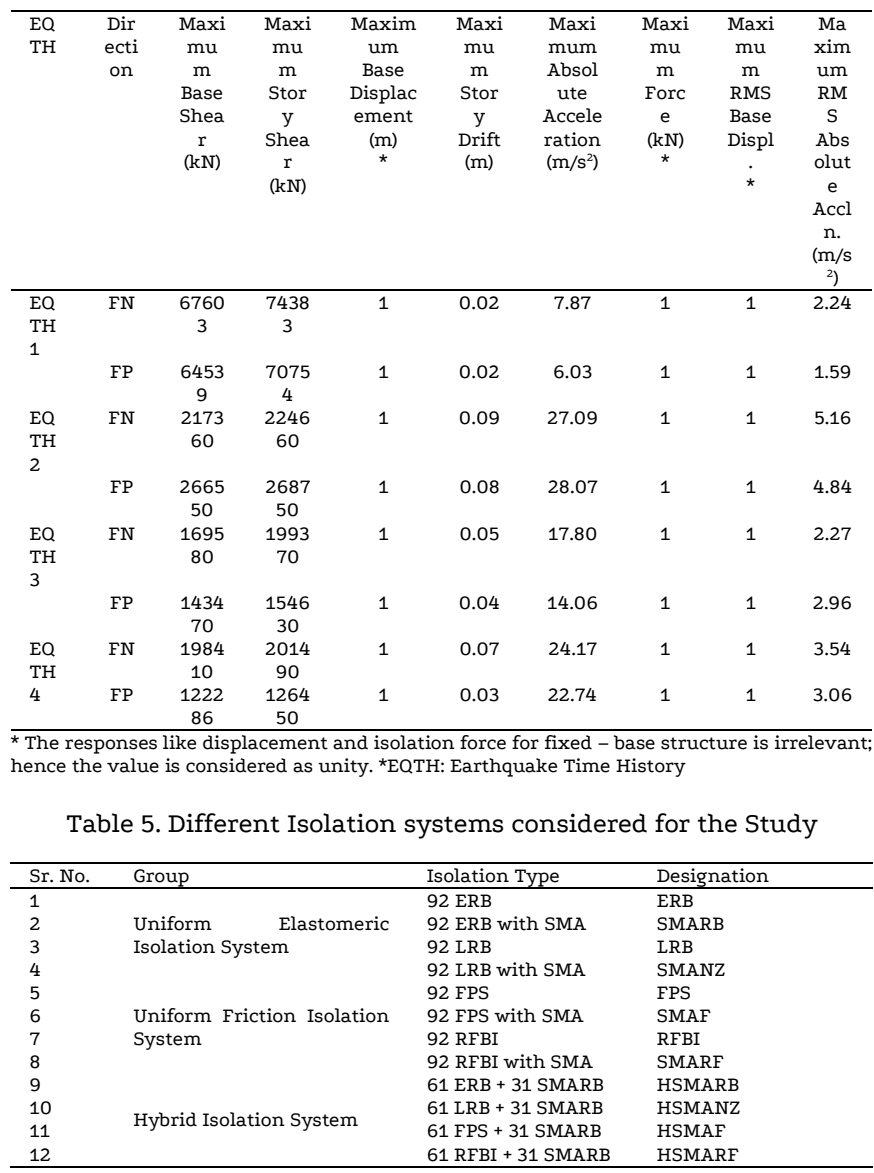

\section{Numerical Study}

The different base isolation systems models with SMA are studied, mathematically modelled in MATLAB and its performance is compared through normalized peak structural performance evaluation criteria and time history variations of top floor absolute accelerations; base displacement; story drifts and base shears under the bi-directional excitations of four strong earthquakes. As shown in Table 4 the complete base isolation systems are basically divided into three parts, viz uniform elastomeric isolation system, uniform friction isolation system and hybrid isolation system. Each consisting of four cases each, thus comprising total 12 cases of isolation system. The time history analysis of the benchmark building has been conducted using proposed SMA supplemented isolators which are compared with traditional isolators. The total of 92 isolators are required for uniform isolation system of benchmark building. It is established that hybrid isolation is effective in reducing the superstructure displacement; Monzon et. al. (2012) [22]. Hence, an attempt is made here to study hybrid isolation system which consists of bearing combinations of 31 SMA + Each 61 (ERB, LRB, FPS, R-FBI) isolation systems.

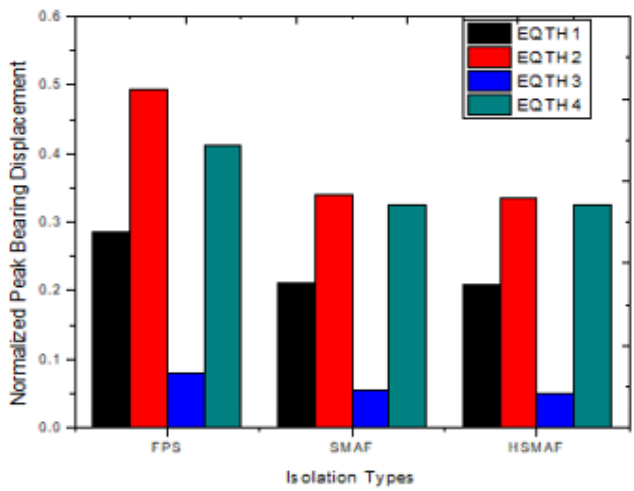

Figure 11. Variation of Normalized Peak Base Displacement for different Earthquakes and Isolation Types 


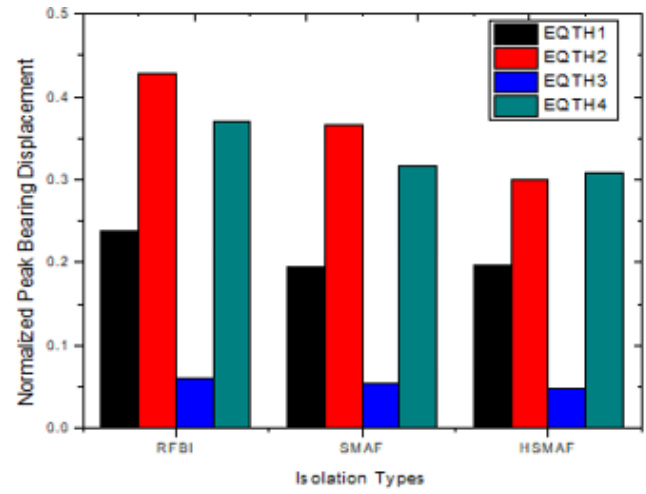

Figure 12. Variation of Normalized Peak Base Displacement for different Earthquakes and Isolation Types

The arrangements of bearings are shown in Fig.1 (a). Four strong earthquakes under bidirectional excitations as tabulated in Table 2 are selected for checking performance of the seismic response of the base-isolated benchmark building. The earthquake ground motions are applied bi-directionally such that the fault normal (FN) and fault parallel (FP) directions of earthquakes are applied in $x$ and $y$ directions of the structure respectively. The performance of different isolation systems are compared on the basis of time history responses and reduction in percentage in evaluation criteria (as tabulated in Table 3). The results so obtained are tabulated in Table 6. Due to space unavailability, the comparison of only ERB, SMARB and HSMARB is shown. The time history variations of top floor acceleration, basedisplacement, story-drift between base-slab and first-floor and baseshear in both $\boldsymbol{x}$ directions are plotted for various uniform and hybrid base-isolation systems as tabled in Table 5 . The base shear time history plot in Fig. 3 shows reduction in base shear values up to $50 \%$ for HSMARB as compared to traditional isolators. The story-drift between base slab and first floor time history plot (Fig. 4) shows difference between traditional isolators and SMARB isolators and it is worthwhile. One can observe lower values of story drifts at peaks for SMARB as compared to traditional isolators. Zero residual displacement is clearly seen.

Fig. 5 to Fig. 8 shows variation of normalized peak acceleration with different earthquakes and isolation types. It is found that SMARB and HSMARB gives less peak acceleration as compared to traditional bearings. Fig. 9 to Fig. 13 shows variation of normalized peak base displacement with different earthquakes and isolation types, as listed in Table 2 and Table 5, respectively. It is demonstarted that SMARB and HSMARB gives less displacemnt than other traditional bearings. It is concluded that HSMARB outperforms than other traditional bearings and combinations thereof.

The time variation of the absolute accelerations of top floor have been plotted in $\mathrm{x}$ direction, in Fig. 13 (a) for the isolation systems as mentioned in Table 5 and for Sylmar earthquake. Also it is compared with fixed base responses for the same Sylmar earthquake. In this Fig.13 (a), red dotted line corresponds to the fixed base response which is reduced by all the three isolation cases.
Table 6. Comparison of ERB, SMARB and HSMARB system in different earthquakes

\begin{tabular}{|c|c|c|c|c|c|c|c|c|c|}
\hline $\begin{array}{l}\mathrm{E} \\
\mathrm{a} \\
\mathrm{r} \\
\mathrm{t} \\
\mathrm{h} \\
\mathrm{q} \\
\mathrm{u} \\
\mathrm{a} \\
\mathrm{k} \\
\mathrm{e}\end{array}$ & $\begin{array}{l}\text { Isolati } \\
\text { on } \\
\text { Type }\end{array}$ & $\mathrm{J}_{1}$ & $\mathrm{~J}_{2}$ & $\mathrm{~J}_{3}$ & $\mathrm{~J}_{4}$ & $\mathrm{~J}_{5}$ & $J_{6}$ & $\mathrm{~J}_{7}$ & $J_{8}$ \\
\hline $\begin{array}{l}\mathrm{E} \\
\mathrm{Q} \\
\mathrm{T} \\
\mathrm{H} \\
1\end{array}$ & ERB & 0.379 & 0.376 & 0.831 & 0.374 & 0.232 & 0.372 & 0.335 & 0.530 \\
\hline & $\begin{array}{c}\text { SMAR } \\
\text { B }\end{array}$ & $\begin{array}{l}0.24 \\
6(35)\end{array}$ & $\begin{array}{c}0.236 \\
(37)\end{array}$ & $\begin{array}{l}0.42 \\
2(49)\end{array}$ & $\begin{array}{c}0.274 \\
(27)\end{array}$ & $\begin{array}{c}0.214 \\
(8)\end{array}$ & $\begin{array}{c}0.239 \\
(36)\end{array}$ & $\begin{array}{c}0.105 \\
(69)\end{array}$ & $\begin{array}{l}0.24 \\
2(54)\end{array}$ \\
\hline & $\begin{array}{c}\text { HSMA } \\
\text { RB }\end{array}$ & $\begin{array}{l}0.24 \\
4(36)\end{array}$ & $\begin{array}{c}0.237 \\
(37)\end{array}$ & $\begin{array}{c}0.487 \\
(41)\end{array}$ & $\begin{array}{c}0.241 \\
(36)\end{array}$ & $\begin{array}{c}0.180 \\
(23)\end{array}$ & $\begin{array}{c}0.227 \\
(39\end{array}$ & $\begin{array}{c}0.138 \\
(59)\end{array}$ & $\begin{array}{c}0.218 \\
(59)\end{array}$ \\
\hline $\begin{array}{l}\mathrm{E} \\
\mathrm{Q} \\
\mathrm{T} \\
\mathrm{H} \\
2\end{array}$ & ERB & 0.251 & 0.222 & $\begin{array}{c}0.70 \\
9\end{array}$ & 0.152 & 0.136 & $\begin{array}{c}0.30 \\
8\end{array}$ & 0.355 & 0.295 \\
\hline & $\underset{\mathrm{B}}{\mathrm{SMAR}}$ & $\begin{array}{c}0.199 \\
(21)\end{array}$ & $\begin{array}{c}0.184 \\
(17)\end{array}$ & $\begin{array}{c}0.436 \\
(39)\end{array}$ & $\begin{array}{c}0.173 \\
(-13)\end{array}$ & $\begin{array}{l}0.177 \\
(-30)\end{array}$ & $\begin{array}{c}0.256 \\
(17)\end{array}$ & $\begin{array}{l}0.08 \\
6(76)\end{array}$ & $\begin{array}{c}0.116 \\
(61)\end{array}$ \\
\hline & $\begin{array}{c}\text { HSMA } \\
\text { RB }\end{array}$ & $\begin{array}{l}0.22 \\
0(13)\end{array}$ & $\begin{array}{c}0.20 \\
5(8)\end{array}$ & $\begin{array}{c}0.482 \\
(32)\end{array}$ & $\begin{array}{c}0.158 \\
(-4)\end{array}$ & $\begin{array}{c}0.152 \\
(-12)\end{array}$ & $\begin{array}{c}0.282 \\
(8)\end{array}$ & $\begin{array}{c}0.119 \\
(67)\end{array}$ & $\begin{array}{c}0.111 \\
(62)\end{array}$ \\
\hline $\begin{array}{l}\mathrm{E} \\
\mathrm{Q} \\
\mathrm{T} \\
\mathrm{H}\end{array}$ & ERB & 0.576 & $\begin{array}{c}0.48 \\
4\end{array}$ & 0.789 & 0.399 & 0.198 & 0.354 & $\begin{array}{c}0.43 \\
0\end{array}$ & $\begin{array}{c}0.69 \\
0\end{array}$ \\
\hline & $\begin{array}{c}\text { SMAR } \\
\text { B }\end{array}$ & $\begin{array}{c}0.342 \\
(41)\end{array}$ & $\begin{array}{c}0.284 \\
(41)\end{array}$ & $\begin{array}{c}0.454 \\
(42)\end{array}$ & $\begin{array}{c}0.252 \\
(37)\end{array}$ & $\begin{array}{c}0.125 \\
(37)\end{array}$ & $\begin{array}{c}0.214 \\
(40)\end{array}$ & $\begin{array}{c}0.119 \\
(72)\end{array}$ & $\begin{array}{c}0.282 \\
(59)\end{array}$ \\
\hline & $\begin{array}{c}\text { HSMA } \\
\text { RB }\end{array}$ & $\begin{array}{c}0.332 \\
(42)\end{array}$ & $\begin{array}{c}0.293 \\
(39)\end{array}$ & $\begin{array}{c}0.381 \\
(52)\end{array}$ & $\begin{array}{c}0.243 \\
(39)\end{array}$ & $\begin{array}{c}0.133 \\
(33)\end{array}$ & $\begin{array}{l}0.20 \\
3(43)\end{array}$ & $\begin{array}{c}0.165 \\
(62)\end{array}$ & $\begin{array}{c}0.233 \\
(66)\end{array}$ \\
\hline $\begin{array}{l}\mathrm{E} \\
\mathrm{Q} \\
\mathrm{T} \\
\mathrm{H} \\
4\end{array}$ & ERB & 0.201 & 0.179 & 0.431 & 0.163 & 0.128 & 0.187 & 0.155 & 0.213 \\
\hline & $\underset{B}{\text { SMAR }}$ & $\begin{array}{c}0.165 \\
(18)\end{array}$ & $\begin{array}{l}0.14 \\
0(21)\end{array}$ & $\begin{array}{c}0.289 \\
(33)\end{array}$ & $\begin{array}{c}0.19 \\
0(- \\
16)\end{array}$ & $\begin{array}{c}0.170 \\
(-32)\end{array}$ & $\begin{array}{c}0.161 \\
(14)\end{array}$ & $\begin{array}{l}0.06 \\
9(56)\end{array}$ & $\begin{array}{c}0.154 \\
(28)\end{array}$ \\
\hline & $\begin{array}{c}\text { HSMA } \\
\text { RB }\end{array}$ & $\begin{array}{c}0.170 \\
(16)\end{array}$ & $\begin{array}{c}0.145 \\
(19)\end{array}$ & $\begin{array}{l}0.32 \\
0(26\end{array}$ & $\begin{array}{c}0.165 \\
(-1)\end{array}$ & $\begin{array}{c}0.144 \\
(-12)\end{array}$ & $\begin{array}{c}0.164 \\
(12)\end{array}$ & $\begin{array}{l}0.08 \\
6(44)\end{array}$ & $\begin{array}{c}0.167 \\
(22)\end{array}$ \\
\hline
\end{tabular}
compared to traditional ERB case, respectively.

However, the reduction in response corresponding to SMARB (represented by magenta line) is appreciable compared to other traditional isolators. It is also observed that SMARB shows reduction in acceleration as compared to traditional ERB. There is little difference between hybrid and uniform combinations of the isolation systems with respect to acceleration. Table 6 shows the comparison of performance evaluation criteria values for various uniform and hybrid isolation system. The SMARB isolation system increases the acceleration values by $7-22 \%$ than the ERB system except for Sylmar earthquakes. But, HSMARB system increases the acceleration values only up to $5-8 \%$. 


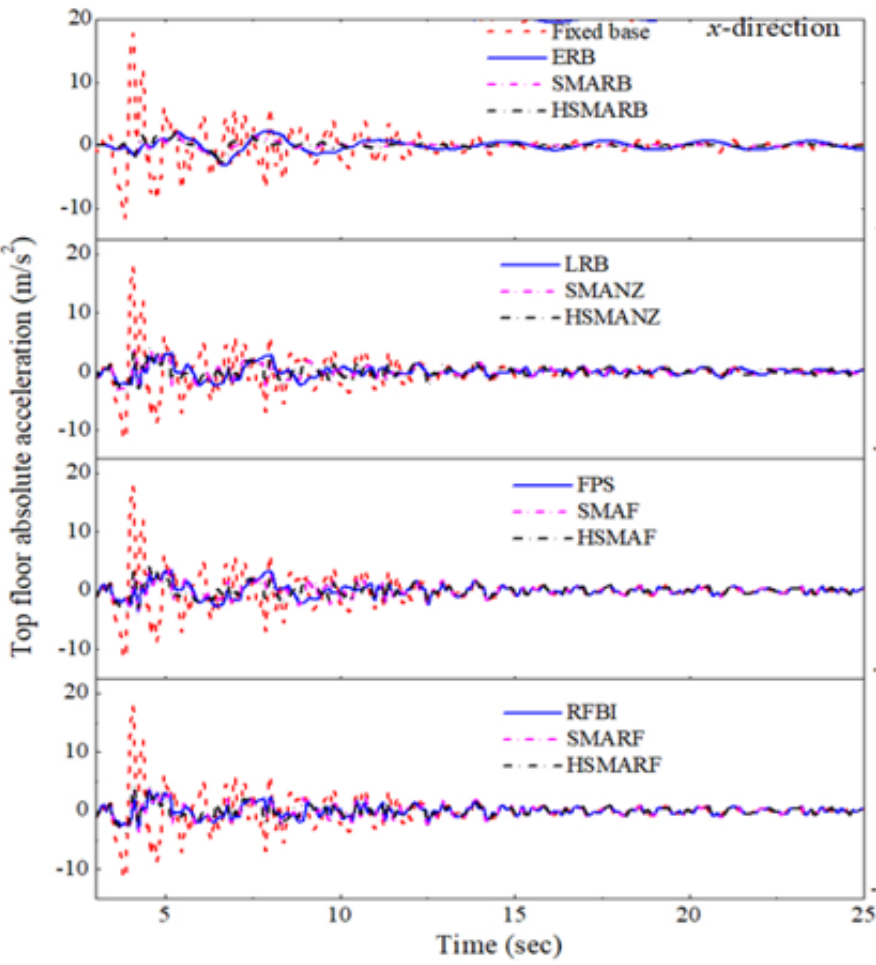

(a)

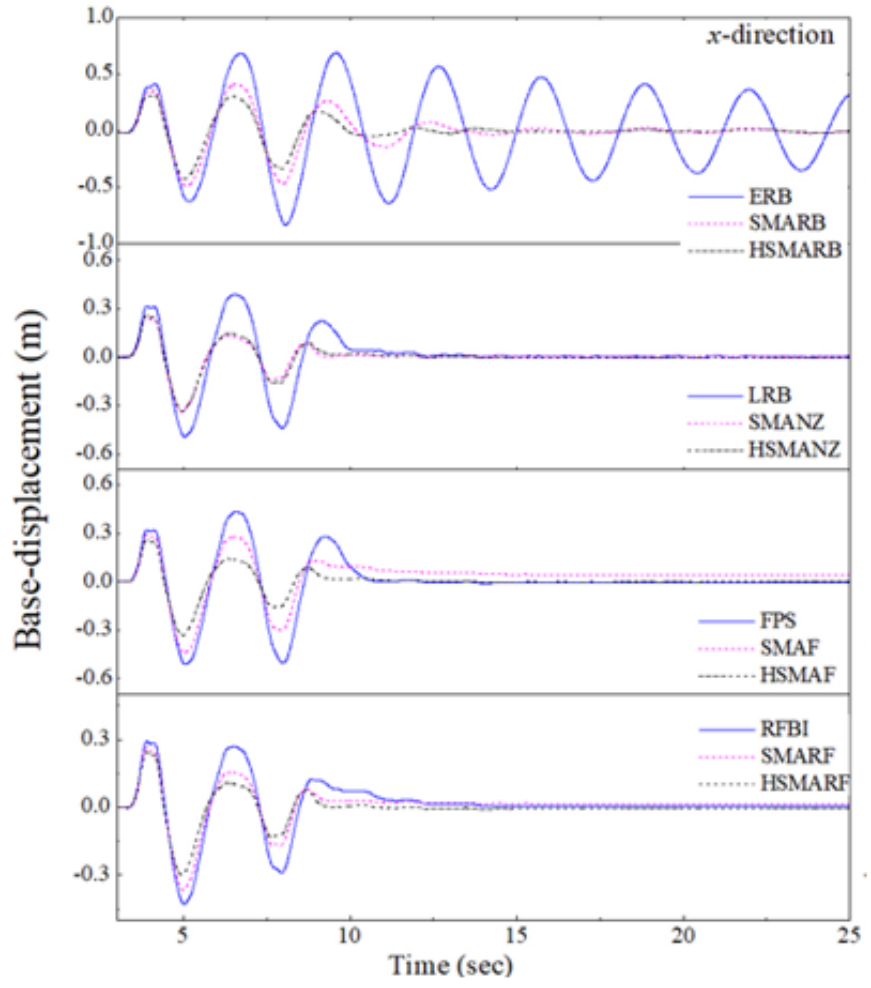

(b)

Figure 13. Time Variation of a) Top - Floor acceleration b) Base Displacement for base-isolated building under Sylmar, 1994 earthquake

In Fig. 13 (b), base displacement time history response is shown. As clearly seen in Fig. 5, reduction in base displacement is better with SMARB. SMARB shows $41 \%$ reduction in base displacement as compared to ERB; whereas HSMARB shows $51 \%$ reduction. There is negligible difference in base displacement reduction using SMANZ and HSMANZ as compared to SMARB and HSMARB. In uniform friction based isolation system, uniform SMARF shows 33\% reduction in base displacement as compared to uniform FPS whereas hybrid combination HSMAF shows $36 \%$ reduction in base displacement. Thus, it is proved that addition of SMA in traditional isolators is beneficial from reduction in seismic response point of view.

\section{Concluding Remarks}

This study emphasizes the effectiveness of using smart materials for base isolation and therefore the following conclusions are made.

- The seismic response control using SMA with traditional isolators is proved effective for base isolated benchmark building.

- The bearing displacements reduced effectively using SMA supplemented bearings. The structural response also improved better than traditional bearings.

- The hybrid isolation system having combination of SMA + ERB system is proved to be excellent among other combinations of traditional isolation systems.

- The hybrid isolation system having combination of SMA + Lead Rubber Bearing (LRB) is not so effective in seismic response control. It is able to control displacement but increases the acceleration, base shear, story drift and isolation forces. This is so because SMA and lead serves same purpose in bearings.

- The SMAF (having hybrid combination of SMA and Friction Pendulum System) performed better as compared to Reduced Friction Bearing Isolator (RFBI) combination with SMA with respect to control of isolator displacement.

\section{Acknowledgement}

The author would like to thank all the people at IIT Bombay, COEP Pune, Govt. of India, and Govt. of Maharashtra who have helped directly or indirectly in this research work.

\section{Declaration of Conflict of Interests}

The author declares that there is no conflict of interest. The author has no known competing financial interests or personal relationships that could have appeared to influence the work reported in this paper. 


\section{References}

[1.] Jangid R. S., NPTEL web Course on "Introduction to Earthquake Engineering", (2003) http://nptel.iitm.ac.in.

[2.] Park K. S., Jung H. J. and Lee I. W., "A comparative study on aseismic performances of base isolation systems for multi-span continuous bridge". Engineering Structures, Elsevier,24 (2002)1001 - 1013.

[3.] Su, L., Ahmadi, G., and Tadjbakhsh, I. G., "Comparative study of base isolation systems". Journal of Engineering Mechanics, 115(9), (1989a)1976-1992.

[4.] Su, L., Ahmadi, G., and Tadjbakhsh, I. G., "A comparative study of performances of various base isolation systems, part i: Shear beam structures". Earthquake Engineering and Structural Dynamics, 18,(1989b)11-32.

[5.] Filiatrault A. and Cherry S., "Comparative Performance of Friction Damped Systems and Base Isolation Systems for Earthquake Retrofit and Aseismic Design", Earthquake Engineering and Structural Dynamics, Vol. 16, (1988)389 - 416

[6.] Narasimhan, S. Nagarajaiah, E. A. Johnson And H. P. Gavin "Smart Base-Isolated Benchmark Building. Part III", Structural Control and Health Monitoring 13, (2006)573-588.

[7.] Graesser, E. and Cozzarelli, F., "Shape-memory alloys as new materials for aseismic isolation". Journal of Engineering Mechanics, (ASCE), 117, (1991)2590-2608.

[8.] Wilson, J. C. and Wesolowsky, M. J., "Shape memory alloys for seismic response modification: A state-of-the-art review". Earthquake Spectra, 21, (2005)8755-2930.

[9.] Ozbulut, O. E., Hurlebaus, S., and Desroches, R., "Seismic Response ControlUsing Shape Memory Alloys: A Review". Journal of Intelligent Material Systems and Structures, 22, (2011)1531-1549.

[10.]Ozbulut, O. E., Roschke, P. N., Lin, P. Y., and Loh, C. H., GA-based optimum design of a shape memory alloy device for seismic response mitigation. Smart Materials and Structures,19, (2010)065004.

[11.]Graesser, E. and Cozzarelli, F., "A Proposed Three Dimensional Constitutive Model for Shape Memory Alloy". Journal of Intelligent Material Systems and Structures, Vol.5 - January 1994, (1994)78-89.

[12.]Wilde, K., Gardoni, P., and Fujino, Y., "Base isolation system with shape memory alloy device for elevated highway bridges". Engineering Structures, 22, (2000)222 - 229.

[13.]Ren, W., Li, H., and Song, G., A one-dimensional strain-ratedependent constitutive model for superelastic shape memory alloys. Smart Materials and Structures, 16, (2007)191-197.

[14.]Ghodke S. and Jangid R. S., "Equivalent Linear Elastic-Viscous Model of Shape Memory Alloy for Isolated Structures", Journal of Advances in Engineering Software, Elsevier, Science Direct, 99(2016)1-8

[15.]Skinner, R., J.M., K., and A.J., H., Hysteretic dampers for earthquake resistant structures. Earthquake Engineering and Structural Dynamics, 3, (1975)287-296.

[16.]Robinson W. H., "Seismic Isolation of Civil Buildings in New Zealand", John Wiley and Sons, Ltd, Progress in Structural Engineering and Materials, 2000 (2), (2000)328-334.
[17.]Matsagar, V. A. and Jangid, R. S., "Influence of isolator characteristics on the response of base-isolated structures". Engineering Structures, 26, (2004)1735 - 1749.

[18.]Jangid R. S., “Optimum lead - rubber isolation bearings for nearfault motions". Engineering Structures, 29 (2007)2503 - 2513.

[19.]Mostaghel N. and Khodaverdian, "Dynamics of Resilient-Friction Base Isolator (R-FBI)". Earthquake Engineering and Structural Dynamics, Vol. 15, (1987)379 - 390.

[20.] Mostaghel N. and Mortazavi, "An Assesment of Seaonc Draft Code for Resilient Sliding Isolators". Earthquake Engineering and Structural Dynamics, Vol. 20, (1991)523 - 533.

[21.]Jangid, R. S. and Kelly, J. M., Base isolation for near-fault motions. Earthquake Engineering and Structural Dynamics, 30, (2001)691707.

[22.]Monzon, E., Wei, C., Buckle, I., and Itani, A., Seismic Response of Full and Hybrid Isolated Curved Bridges, chapter 54, pages (2012)603-612.

\section{How to Cite This Article}

Akhare, A.R., Mitigation of Earthquake Responses Using SMA Supplemented Base-Isolation Devices for Benchmark Building, Civil Engineering Beyond Limits, 4(2021),22-30. https://doi.org/10.36937/cebel.2021.004.005 